\title{
Freehand Ultrasound-Guided Transperineal Prostate Biopsy: Technique and Early Results
}

John Michael DiBianco, BS

Ross University School of Medicine, Roseau, Commonwealth of Dominica, West Indies.

Mathew Allaway, Do

Urology Associates, Cumberland, Maryland.

E-mail: urologyassociates@icloud.com

(c) Mary Ann Liebert, Inc. DOI: 10.1089/vid.2014.0046
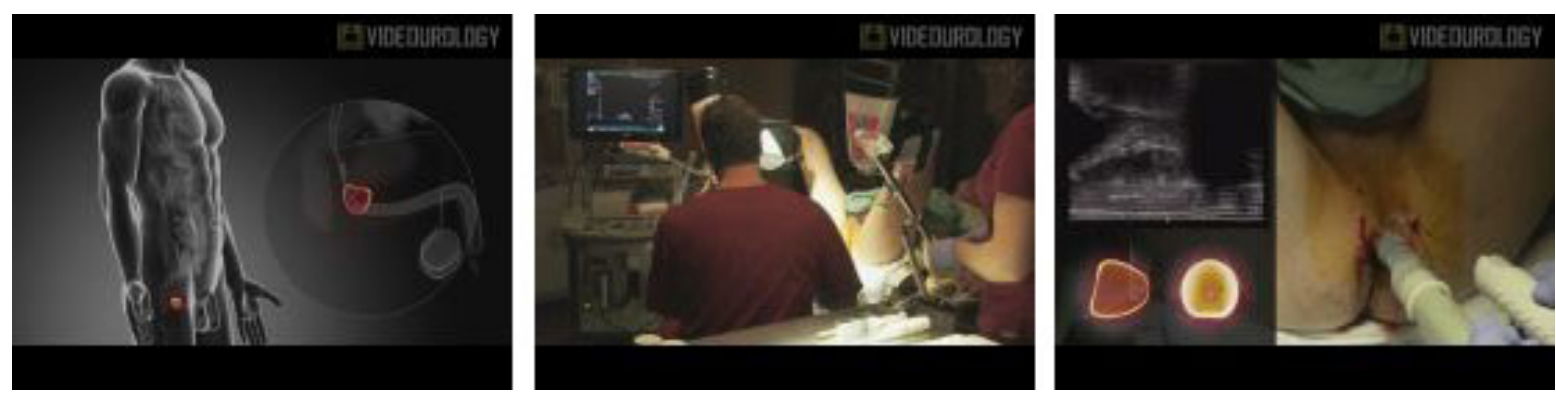

\section{Abstract}

Introduction: Approximately 1 million prostate biopsies are performed yearly, the vast majority of which are performed transrectally. ${ }^{1}$ Passing biopsy needles through the rectal wall introduces bacteria into the prostate parenchyma. ${ }^{2}$ The resistance of coliform bacteria to fluoroquinolone antibiotics is as high as $22 \%,{ }^{2,3}$ and the infectious complications have increased to as high as $7 \%$ with hospitalization risk as high as $4 \% .{ }^{4}$ I demonstrate a technique avoiding this infectious risk by passing the biopsy needle through the perineum using a freehand technique under ultrasound monitoring.

Materials and Methods: All procedures were performed in the Ambulatory Urology Surgical Center (Cumberland, MD) by one urologist. Patients requiring prostate biopsy, in accordance with accepted standards of urologic care, were offered the option of sedation and/or local anesthesia. Patients did not receive bowel preparation, prior rectal swab, or pre-/postoperative antibiotics. Intravenous access was obtained for a weight-based dose of cefazolin and propofol-induced procedural anesthesia. Patients were draped in a dorsal lithotomy position, using tape to secure the penis and testicles. A povidoneiodine swab, $10 \%$, was used to prepare the perineum. Transrectal ultrasound with the BK US probe (BK Medical) of the prostate was performed for measurement and identification of potentially pathological regions. A 14-gauge needle was placed into the perineum at the midprostate. Approximately $10 \mathrm{~mL}$ of $2 \%$ lidocaine was infiltrated into the skin, subcutaneous tissue, and pelvic floor. Under ultrasound supervision, the Bard 18-gauge biopsy gun (Bard Max-Core22 mm; Bard Medical) was placed and reintroduced through the 14-gauge needle into the prostate, with ultrasound confirmed tip location. Three separate regions of the prostate (far lateral, middle, and apical) were sampled. Based on the size of the prostate gland, two to four tissue samples were obtained from each region and placed in separate specimen containers. Pressure was applied to the perineum and a small amount of bacitracin was applied to the puncture site. The procedure was repeated for the opposite side. Patients were discharged following recovery from propofol anesthesia. Patients were instructed to avoid lifting for 24 hours. Patients were called 2 days after the procedure to report the biopsy results to them, schedule follow-up office visits, if necessary, answer questions, and identify problems.

Results: Two hundred thirteen patients underwent ultrasound-guided freehand transperineal prostate biopsy from January 2012 to October 2013. All patients opted for sedation. Biopsy was performed within 10 minutes, and total room time within 15 minutes. None of the patients suffered any postoperative 
physician or hospital intervention nor experienced any complication $\geq$ Clavien Grade I. ${ }^{5}$ All episodes of hematuria were self-limiting.

Conclusions: Ultrasound-guided freehand transperineal prostate biopsy represents a safe and accurate alternative to transrectal biopsy. Previously described transperineal approaches often use a higher degree of anesthesia, unique equipment not routinely available, more personnel, and more time than the traditional transrectal approach. ${ }^{6}$ The technique described above uses the same equipment as the traditional transrectal technique except for a 14-gauge needle and may feasibly be performed under local anesthesia. ${ }^{7,8}$ This procedure can be performed safely within the time frame usually allotted for a transrectal technique with an incidence of infection and hospitalization of zero.

Acknowledgments: The authors would like to acknowledge and sincerely thank Mr. David Romeo and Vibrant Image Photography \& Design for magnificent videography, cinematography, editing, and formatting of the video. They truly could not have made this possible without his help.

The authors declare that no competing financial interests exist.

Runtime of video: 7 mins 54 secs

\section{Cite this video}

John Michael DiBianco, Mathew Allaway, Freehand Ultrasound-Guided Transperineal Prostate Biopsy: Technique and Early Results, J Endourol Part B Videourology. 2014, DOI: 10.1089/vid.2014.0046.

\section{References}

1. Loeb S, Carter HB, Berndt SI, et al. Complications after prostate biopsy: Data from SEER-Medicare. J Urol 2011;186:1830-1834.

2. Liss MA, Chang A, Santos R, et al. Prevalence and significance of fluoroquinolone resistant Escherichia coli in patients undergoing transrectal ultrasound guided prostate needle biopsy. J Urol 2011;185:1283-1288.

3. Batura D, Rao GG, Nielsen PB. Prevalence of antimicrobial resistance in intestinal flora of patients undergoing prostatic biopsy: Implications for prophylaxis and treatment of infections after biopsy. BJU Int 2010;106:1017-1020.

4. Nam RK, Saskin R, Lee Y, et al. Increasing hospital admission rates for urological complications after transrectal ultrasound guided prostate biopsy. J Urol 2013;189:S12-S17.

5. Dindo D, Demartines N, Clavien PA. Classification of surgical complications: A new proposal with evaluation in a cohort of 6336 patients and results of a survey. Ann Surg 2004;240:205-213.

6. Shinohara K, Gulati M, Koppie T, et al. Transperineal prostate biopsy after abdominoperineal resection. J Urol 2003;169:141-144.

7. Iremashvili VV, Chepurov AK, Kobaladze KM, et al. Periprostatic local anesthesia with pudendal block for transperineal ultrasound-guided prostate biopsy: A randomized trial. Urology 2010;75:1023-1027.

8. Kubo Y, Kawakami S, Numao N, et al. Simple and effective local anesthesia for transperineal extended prostate biopsy: Application to three-dimensional 26-core biopsy. Int J Urol 2009; 16:420-423.

Original Publication Date: 2014 